\title{
Cable Tie Seton in Surgical Treatment of High Perianal Fistula
}

El-Sayed Ahmed Mohammed Awad Ammar, Adel Mohammad Abdulhaleim Lasheen, Ahmed Shawki Abd-El-Aziz

General Surgery department, Faculty of Medicine, Al-Azhar University, Cairo, Egypt

Corresponding Author: El-Sayed Ahmed Mohammed Awad Ammar, Email: ammargermany85@gmail.com., Tel.01030244881

\begin{abstract}
:
Background: Seton is any string-like material which when tied through the fistula tract causes an inflammatory reaction which stimulates fibrosis that fixes and prevents retraction of the sphincter continuity when it is divided. In this way, it maintains sphincter continuity during cutting process. Aim of work: was to evaluate the cable tie seton technique in surgical treatment of high perianal fistula, regarding the rate of fecal incontinences and recurrence. Patients and Methods: This prospective study included a total of 20 cases having single tract, high perianal fistula, primary or recurrent and who were managed by cable tie seton from October 2016 till September 2017. Patients were enrolled from General Surgery Department, AlHussein Hospital. Patients were instructed to follow up weekly for 10 weeks with continuous tightening of the seton. Results: All the patients were followed up for the state of incontinence for flatus, liquid and solid stool and follow up for recurrence, slippage of cable: Incontinence: There is 3 cases noticed in early 2 weeks incontinent for flatus. Incontinence for liquid stool noticed in 2 cases in early 1 week. Incontinence for solid stool not noticed in our study. In all cases, the cable tie seton was kept in its position and didn't dislodged or slipped. Conclusion: It could be concluded that cable tie seton is safe, low cost, ubiquitous, pragmatic, precise, and accost effective option for the treatment of high perianal fistula. We there for recommended it for treating fistula in ano requiring the placement of aseton. It does not carry the disadvantages of repeated anesthesia and visits to the operating theater and reduce the morbidity, inconvenience, and cost to the patient.
\end{abstract}

Keywords: ACPGBI: Association of Coloproctology of Great Britain and Ireland; AFP: Anal fistula plug; EAS: External anal sphincter; IAS: Internal anal sphincter

\section{INTRODUCTION:}

Fistula-in-ano is one of the commonly encountered surgical problems with prevalence of 1.2 to $2.8 / 10,000$. The classification of fistula-inano, as described by Parks $\boldsymbol{e t}$ al. is based on the location of its tract in relation to anal sphincter muscle: intersphincteric, transsphincteric, suprasphincteric, or extrasphincteric ${ }^{(1)}$. The term complex fistula is modification of the Park's classification, which falls in any one of these conditions, that is, the track crosses $>30 \%$ to $50 \%$ of the external sphincter, anterior in females, multiple tracks, recurrent, or the patient has preexisting incontinence, local irradiation, or Crohn's disease. Due to the involvement of the anal sphincter, the treatment of complex fistula poses a high risk for impairment of continence ${ }^{(2)}$. Due to the lack of a single appropriate technique for the treatment of fistula-in-ano, treatment must be navigated by the surgeon's experience and judgment. The surgeon has to keep in mind the tradeoff between the extent of sphincter division, postoperative healing rate, and functional $\operatorname{loss}^{(3)}$. Whatever the type and the extent of fistula are, the principles of anal fistula surgery are to get rid of the fistula, prevent recurrence, and preserve sphincter function. Most of the fistula-in-ano has been conventionally treated by either fistulotomy, or fistulectomy, which have been proven to be effective $^{(4)}$.Seton have been used to manage anal fistula from hundreds of years; however, in the literature, setons were commonly used only for high or complex anal fistula in order to avoid fecal incontinence and recurrence ${ }^{(5)}$. Seton is any string-like material which when tied through the fistula tract causes an inflammatory reaction which stimulates fibrosis that fixes and prevents retraction of the sphincter continuity when it is divided. In this way, it maintains sphincter continuity during cutting process ${ }^{(6)}$. Different types of setons are used for this purpose like silastic tube, silk, linen, braided silk, rubber band, braided polyester, vascular loop, polypropylene, nylon, cable tie, and so forth ${ }^{(6)}$. The reported incontinence and recurrence rate ranges from $0 \%$ to $25 \%$. Ritchie et al. ${ }^{(6)}$. and from $0 \%$ to $16 \%{ }^{(7)}$. respectively, with different materials used as seton. The cable tie is very cheap, easily inserted, and provides convenient tightening in a clinic setting without need of analgesia which even can be done by the attendants if they are trained onc.

The aim of the current work was to evaluate the cable tie seton technique in surgical treatment of high perianal fistula, regarding the rate of fecal incontinences and recurrence. 


\section{PATIENTS AND METHODS}

This prospective study included a total of 20 cases who have single tract, high perianal fistula, primary or recurrent and who were managed by cable tie seton attending at General Surgery Department, Al-Hussein University Hospitals. Approval of the ethical committee and a written informed consent from all the subjects were obtained. This study was conducted between October 2016 till September 2017.

Patients were instructed to follow up weekly for 10 weeks with continuous tightening of the seton. All patients were informed that they were going to be enrolled in a clinical trial and counseled about the method of dealing with the fistula and the fact that healing and /or convalescence is likely to be prolonged. For each patient detailed history, complete clinical examination, usual routine preoperative investigations, detailed blood profile \& illuminated proctoscopy were done. Radiological examination (fistula-graphy and/or MRI) was done for all patients. Systemic antibiotics were started before the operation. Cable tie seton applied for at least 10 weeks during which the patients presented weekly for follow up \& tightening. Follow up of the patients continued to detect any recurrence of symptoms or sign of fistula.

\section{Inclusion criteria:}

Patients presented with single tract high perianal fistula, either denovo or recurrent.

\section{Exclusion criteria:}

Include branched high fistula, patients with chronic inflammatory bowel disease, dermatitis, diabetes, intestinal T.B, anorectal tumor and loss of follow up and pregnant or lactating women. Bowel preparation was done in all patients with clear liquid diet 24 hours prior to surgery and / or clear enema. The majority of the patients preferred to have general anaethesia, albeit spinal and caudal blocks were also used at times. In the operation room, the patients were evaluated in the lithotomy position, Arigid sigmoids copy and proctoscopy were done prior to any intervention. Using proctoscope, roll gauze was placed in the analırectal canal. The internal opening was identified by injecting dye (methlene blue) to the external opening. The roll gauze was withdrawn to identify the depth and position were the opening exists. The external opening was gently probed using flexible blunt metal probe cable till the previously identified internal opening.

\section{Methods of cable insertion}

1. Insertion of cable after fistulectomy for the lower part of fistula: Fistulectomy was done for the low part of the fistula and the cable tie seton was pathing through the tract and then locked ad tightened to make it sit loosely over the sphincter, After achievement of haemostasis, dry gauze dressing was used to cover the wound.

2. Insertion of cable without fistulectomy for the lower part of fistula. Post operatively the pack was removed after 24 hours after sitzbath, the patient discharged home and advised by sitz-bath 3 times daily.

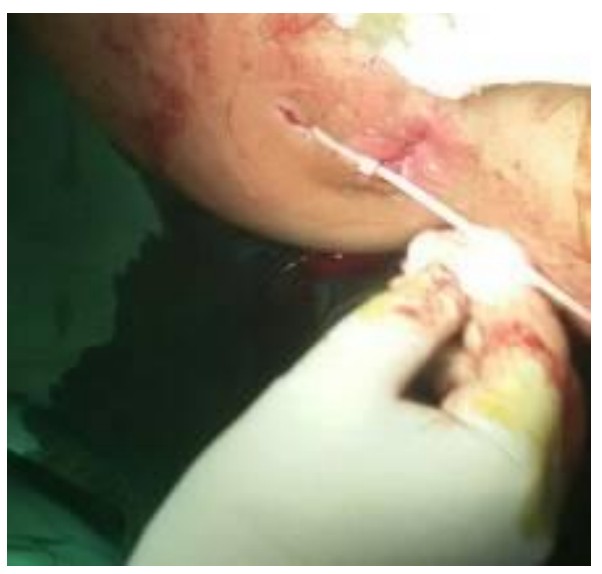

Fig. (1): Tightening of cable

\section{FOLLOW UP:}

Follow up examination and tightening of seton was done every week for at least 10 weeks or until one centimeter sphincter was lefted behind. On each visit the patients were asked about the fecal incontinence. The cable tie was removed by dividing it near the knukle if the cable tie didn't completely cut through despite complete healing of lateral wound or core sphincter a one centimeter diameter was left behind.

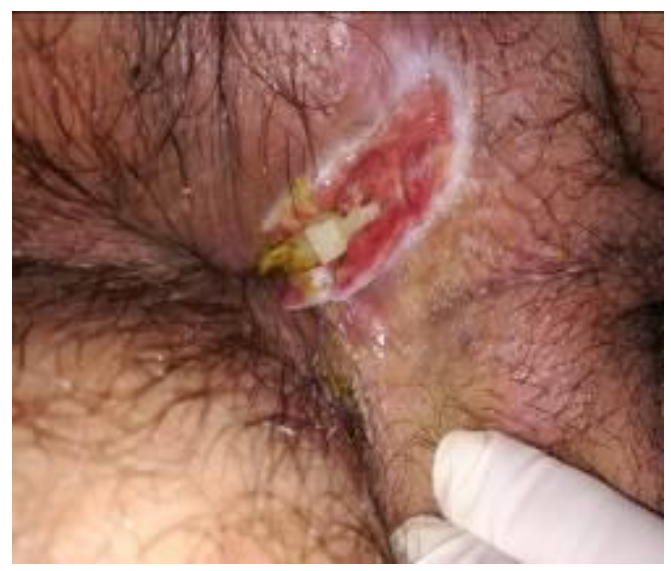

Fig. (2): Picture after tightening of cable

\section{RESULTS}

During the study period mentioned, 20 patients satisfying the selection criteria were treated with 
cable tie seton. Of these patients, $16(80 \%)$ were males and $4(20 \%)$ were females. Patients age ranged from 26 to 60 years (mean41.8 \pm 9.93 ) . Patients were followed-up for a period of 6-12 months. Six patients (30\%) had high transsphincteric , $4(20 \%)$ had supra-sphincteric ,9 patients $(45 \%)$ had inter sphincteric and one case had extra shincteric fistula. 6 (30\%) patients had history of past surgery on perianal fistula, 16 $(30 \%)$ patients gave a history of incision and drainage for perianal abscess. Satisfactory healing was achieved in 20 patients at two and a half months and in all patients (100\%) at three months. Recurrent fistula showed up in $1(5 \%)$ patient. inwards, and the drip set tubing was pulled out from the anal side of the opening. The cable tie was then bolted and tightened to make it sit loosely over the sphincter (which was then within the cycle of seton). The wound was covered with dry gauze dressing. NSAIDs were used as the essential pain killer drug. Patients were then seen in the outpatient clinic after 7-10 days to evaluate wound. The patients were then seen every two weeks and sincerely encouraged to walk as much as they can; at the same time, the cable tie was tightened if found loose. On each clinic visit, patients were questioned about the fecal incontinence using Wexner's score as a model ${ }^{(8)}$. The cable tie was expelled by dividing it near the knuckle if the cable tie did not totally slice through despite complete healing of lateral wound or core sphincter of a centimeter diameter was left behind. Data was analyzed

Table (1): Wexner's score for fecal incontinence.

\begin{tabular}{|l|c|c|c|c|c||}
\hline Characteristic & Never & Rarely & Sometimes & Usually & Always \\
\hline Flatus & 0 & 1 & 2 & 3 & 4 \\
\hline Liquid stool & 0 & 1 & 2 & 3 & 4 \\
\hline Solid stool & 0 & 1 & 2 & 3 & 4 \\
\hline Wear pad & 0 & 1 & 2 & 3 & 4 \\
\hline $\begin{array}{l}\text { Alteratioin } \\
\text { in life style }\end{array}$ & 0 & 1 & 2 & 3 & 4 \\
\hline \hline
\end{tabular}

\section{DISCUSSION}

The outcome of fistula surgery varies widely from case to case and from one surgeon to another. The results depend largely on the complexity of the fistula treated ${ }^{(9)}$. In general, there is hesitation to report poor results. Often there is a reciprocal relationship between the incidence of recurrence and incontinence since cure and continence are competing priorities. Reports with low recurrence rates frequently may cite a higher incidence of incontinence, whereas reports with a higher recurrence rate may describe a low rate of incontinence ${ }^{(9)}$. Postoperative incontin-ence disorders, as a sequel of anal surgery, are sizeable and relevant problems; each surgical proctologist is confronted with from time to time ${ }^{(10)}$. Cable tie seton method is used as a new trial to improve healing by slow sequence cutting of fistula and sphincter which consequently enhance the formation of granulation tissue. This study, showed $0 \%$ incontinence and 5\% recurrence rate in 20 patients treated with cable-tie seton for high perianal fistulae. In any case, it is a single-arm study with no comparison criteria. Diverse sorts of seton materials are present with various rates of recurrence and incontinence. Nonetheless, recurrence and incontinence rate is for the most part subject to expertise and judgment of the operating surgeon ${ }^{(6)}$. Cable tie seton is characterized by being modest, nontoxic/nonallergic, sturdy, in fact simple to tie even in clinic setting, and permits to tight over and over without bringing about agony and without anesthesia (local or general). It is comprised of polyamide (nylon) and has selflocking framework with similarly appropriated clicks, which direct the operator to sufficiently tighten it by simply slipping one end without any need of further help or withdrawal. Subsequent to tightening, no serious agony is experienced by the patients other than couples of minutes; this is a result of the exact and controlled tightening accomplished by cable tie as well as the way that we did not tighten it until we found it loose. This controlled and steady tightening declined the incidence of incontinence and recurrence; be that as it may, to the detriment of moderately longer time of seton set up. No patient griped of troubles in strolling or conveying out activities. The cabletie, once connected with, is self securing and is held in place by the tissues inside the loop. Scraping and irritation of the opposing gluteal tissues were counteracted by a piece of gauze on either side of the free end of the cable-tie ${ }^{(11)}$. Minor disorders of incontinence after fistulotomy have been reported to range from $18 \%$ to $52 \%$ whereas soiling and insufficiency have been reported in as many as 35\% to $45 \%$. The occurrence of continence disorders has been found to be related to the complexity of the fistula and to the level and location of the internal opening ${ }^{(12)}$. Patients with complicated fistula, high openings, posterior openings and fistula extensions have been found to be at higher risk. In the treatment of complicated fistulae and those with high openings, more muscle are divided, thus decreasing anal pressures whereas posterior fistula wounds are associated with higher rates of 
incontinence because of their more circuitous routes. Drainage of extensions may accidentally damage small nerves and create more scar tissue around the anorectum $^{(12)}$. If the edges of the fisulotomy wound do not approximate precisely, the anus may be unable to properly closes, resulting in intermittent leakage of gas and Stool. In addition to these factors, impaired continence was associated with increasing $\operatorname{age}^{(13)}$. Risk factors for a continence disorder after fistula surgery are female sex, age of $>50$ years, high (transsphincteric) anal fistula, type of anal surgery and previous operations ${ }^{(14)}$. The variability of results is mainly due to different definitions of incontinence applied, the morphological diversity of fistulae and previous operations. The rate of continence disorder found positively correlates with the precise clinical recording. Thus, by use of a score. Cavanaugh et al. ${ }^{(15)}$ reported the highest rate of incontinence disorders following fistulotomy (64\%). Recurrence rates following fistulotomy range from 0 to $18 \%{ }^{(16)}$. Inability to locate the primary opening may imply a circuitous tract, spontaneous closure of the primary opening or a microscopic opening. The presence of secondary tracts which can be easily missed accounted for early recurrence in $20 \%{ }^{(17)}$. Recurrence rates following staged repairs utilizing a seton range from 0 to ${ }^{0} .29 \%{ }^{(18)}$. Although recurrence rates following anorectal advancement flaps were initially reported to be low, with longterm follow-up, recurrence rates of $40 \%$ have been reported (2). Early postoperative complications that have been reported following fistula surgery include urinary retention, hemorrhage, fecal impaction, and thrombosed external hemorrhoids which were found to occur in less than $6 \%$ of cases $^{(19)}$. Late post fistula surgery complications, such as pain, bleeding, pruritus, and poor wound healing have been reported in $9 \%$ of patients ${ }^{(20)}$. Other adverse factors shown to influence healing include the presence of a short tract which may make it easier for the fibrin glue plug to become dislodged as well as the presence of a cavity on endoanal ultrasound. The latter was associated with a complication of perianal abscess since the tract may not have been entirely filled with glue. ${ }^{(21)}$. Recently, the use of a bioprosthetic plug made from lyophilized porcine intestinal submucosa has been described for the treatment of complex anal fistulae $^{(22)}$. The Surgisis AFPTM (Cook Surgical Inc, Bloomington, IN), when implanted, is colonized by host tissue cells and blood vessels and thus provides a scaffold to allow infiltration of the patient's connective tissue. The first prospective study comparing the anal fistula plug (AFP) to fibrin glue in 25 patients with high transsphincteric or deeper fistulae found greater success rates with the plug $(87 \%$ vs. $40 \%)$ at 3 months ${ }^{(22)}$. The authors concluded that closure of the primary opening of a fistula tract using a suturable biologic AFP is an effective method of treating anorectal fistulae. Although the technique has appeal for its simplicity and avoidance of sphincter injury, more recent reports, however, have tempered enthusiasm with success rates ranging from 13.9 to $87 \%$. A new sphinctersparing technique has been introduced [ligation of the intersphincteric fistula tract (LIFT)]. The LIFT technique is based on the secure closure of the internal opening and removal of the infected cryptoglandular tissue in the intersphincteric space $^{(23)}$. The only patients not suitable are those with early fistulous abscess in which the intersphincteric tract is not well formed. Postoperatively wounds are cleansed with tap water twice a day and following bowel movements. Patients are given 2 weeks of Ciprofloxacillin and Metronidazole. A pitfall with this technique may be the intersphincteric approach for high tracts especially with horseshoe tracts. Also exposure of the intersphincteric space may damage the internal sphincter. Although there are only a few reports in the literature, success rates of 58-94\% have been reported. In addition, time to failure has ranged from 4 to 64 weeks with a median of 19 weeks ${ }^{(24)}$. In this pilot study, during the follow up period, All the patients were followed up for the state of incontinence for flatus, liquid and solid stool and follow up for recurrence,

1. Incontinence; there is 3 cases noticed in early 2 weeks incontinent for flatus. Incontince for liquid stool noticed in 2 cases in early 1 week. Incontinence for solid stool not noticed in our study.

2. Recurrence; there is one case suffering from recurrent fistula.

In all cases, the cable tie seton was kept in its position and didn't dis loged or slipped. In convenience of discomfort was a common association with the method chosen in this study to apply the seton upon a fistula tract with the promotion of its healing.

The $0 \%$ incontinence in our series of returns to many facts; The sphincter muscle is very smoothly and gradually cut through due to the direct compression effect of the cable-tie and "wearing through" the tissues because of the movements produced by walking, while the depth 
of the tissues have a chance of adhering to each other because of the fibrosis that has occurred which prevent distraction of the sphincter. The factors suspected to be implemented in fistula recurrence may be the complexity and level of the fistula, the presence of a horseshoe extension, the laterality of the external opening, inability of the surgeon to localise the internal opening at initial surgery, and the overall surgical experience of the operator $^{(25)}$. In our study, we identified the internal opening in all the patients without radiological investigations. MRI is a helpful investigation in complex fistulas aiming at finding the fistula tract and its extensions, however, it is a costly investigation and most of the patients operated in our setup are poor and can't afford it. Diverse number of studies have shown different results with recurrence rate from 0 to $18 \%$, while long term incontinence rates can exceed $30 \%{ }^{(26)}$.

Ritchie et al. ${ }^{(6)}$ have concluded that there was no relationship between incontinence and the frequency of tightening, type of seton, or classification of fistula. Thus, we further emphasize the importance of surgeon's experience and the use of a seton having additive qualities as stated above.

\section{Conclusion}

In general cable tie seton is safe, low cost, ubiquitous, pragmatic, precise, and accost effective option for the treatment of high perianal fistula. we there for recommended it to treating fistula in ano requiring the placement of aseton. It does not carry the dis advantages of repeated anesthesia and visits to the operating theater and reduce the morbidity, inconvenience, and cost to the patient.

\section{References}

1- Parks AG and Stitz RW (1976): The treatment of high fistula-in-ano.Dis Colon Rectum.,19:487-499.

2- Mizrahi N, Wexner SD, Zmora O et al. (2002): Endorectal advancement flap: are there predictors of failure? Diseases of the Colon and Rectum,45(12):1616-1621.

3- Kodner IJ, Mazor A, Shemesh EI et al. (1993): Endorectal advancement flap repair of rectovaginal and other complicated anorectal fistulas. Surgery,114 (4):682-690.

4- Seow-Choen F and Nicholls RJ (1992): Anal fistula. British Journal of Surgery, 79(3):197-205.
5- Pearl RK, Andrews JR, Orsay CP et al. (1993): Role of the seton in the management of anorectal fistulas. Diseases of the Colon and Rectum,36(6):573-579.

6- Ritchie RD, Sackier JM, and Hodde JP (2009): Incontinence rates after cutting seton treatment for anal fistula, Colorectal Disease, 11(6): 564- 571.

7- Vial M, Parés D, Pera $M$ and Grande $L$ (2010): Faecal incontinence after seton treatment for anal fistulae with and without surgical division of internal anal sphincter: a systematic review. Colorectal Disease, 12(3):172-178.

8- Vaizey CJ, Carapeti E, Cahill JA and Kamm MA(1999):Prospective comparison of faecal incontinence grading systems,"Gut, 44(1): 77-80.

9- Gordon PH and Nivatvongs $S$ (2007): Principles and Practice of Surgery for the Colon, Rectum and Anus; by Inform Healthcare USA., 13(20): 2855-2857.

10- Ommer A (2006): Operative schließmuskelersatz: dynamische grazilisplastikartificial bowel sphincter-sakralnerven stimulation. Coloproctology, 28:64-69.

11- Vatansev C, Alabaz O, Tekin A et al. (2007): A new seton type for the treatment of anal fistula. Digestive Diseases and Sciences, 52(8): 1920-1923.

12- Van Tets WF and Kuijpers HC (1994): Continence disorders after anal fisulotomy. Dis Colon Rectum, 37:1194-7.

13- Marks CG and Ritchie JK. (1977): Anal fistulas at St. Marks Hospital. Br J Surg.; 64: 84-91.

14- Garcia-Aguilar J, Belmonte C, Wong WD et al. (1996): Anal fistula surgery: factors associated with recurrence and incontinence. Dis Colon Rectum, 39:723.

15- Cavanaugh $M$, Hyman $N$ and Osler $T$ (2002): Fecal incontinence severity index after fistulotomy: a predictor of quality of life. Dis Colon Rectum ,45:349-353

16- Vasilevsky ca and Gordon p (1985): results of treatment of fistula-inano. Dis colon rectum, 28: 255- 31 .

17- Sangwan YP, Rosen L, Reither $\mathrm{R}$ et al. (1994): Is simple fisula in ano simple? Dis Colon Rectum, 37: 885-889.

18- Buchanan G, Halligan S, Williams A et al. (2002): Effect of MRI on clinical outcome of recurrent fistula-in-ano. Lancet, 360:1661-1662.

19- Mazier WP (1971): The treatment and care of anal fistulas: a study of 1000 patients. Dis Colon Rectum,14:134-44. 
20- Fazio VW (1987): Complex anal fistulae. Gastroenterology Clin North Am., 16:93-114.

21- Lindsey I, Smilgin-Humphreys MM, Cunningham C et al. (2002): Arandomized, controlled trial of fibrin glue vs. Conventional treatment for anal fistula. Dis Colon Rectum ,45:1608-1615.

22- Johnson EK, Gaw JU and Armstrong DN(2006): Efficacy of anal fistula plug vs. fibrin glue in closure of anorectal fistulas. Dis Colon Rectum,49:371-376.
23- Rojanasakul A (2009): LIFT procedure: a simplified technique for fistula-in-ano. Tech Coloproctol., 131:237-40.

24- Moloo H and Goldberg SM (2008): Novel correction of intersphincteric perianal fistulas preserves anal sphincter. Presented at the American College of Surgeons, San Francisco.

25- Zbar AP, Ramesh J, Beer-Gabel M et al. (2003):Conventional cutting vs. internal anal sphincter preserving seton for high transsphincteric fistula: a prospective randomized manometric and clinical trial. Techniques in Coloproctology; 7(2): 89-94.

26- Poggio JL (2014): Available from: //http://emedicine. medscape.com / article/ 190234- overview\# aw2aab6c14 